\title{
JUBILEES
}

AND DATES

\section{Nikolai Nikolaevich Rosanov}

\author{
DOI: $10.1134 / \mathrm{S} 0030400 \mathrm{X} 11100018$
}

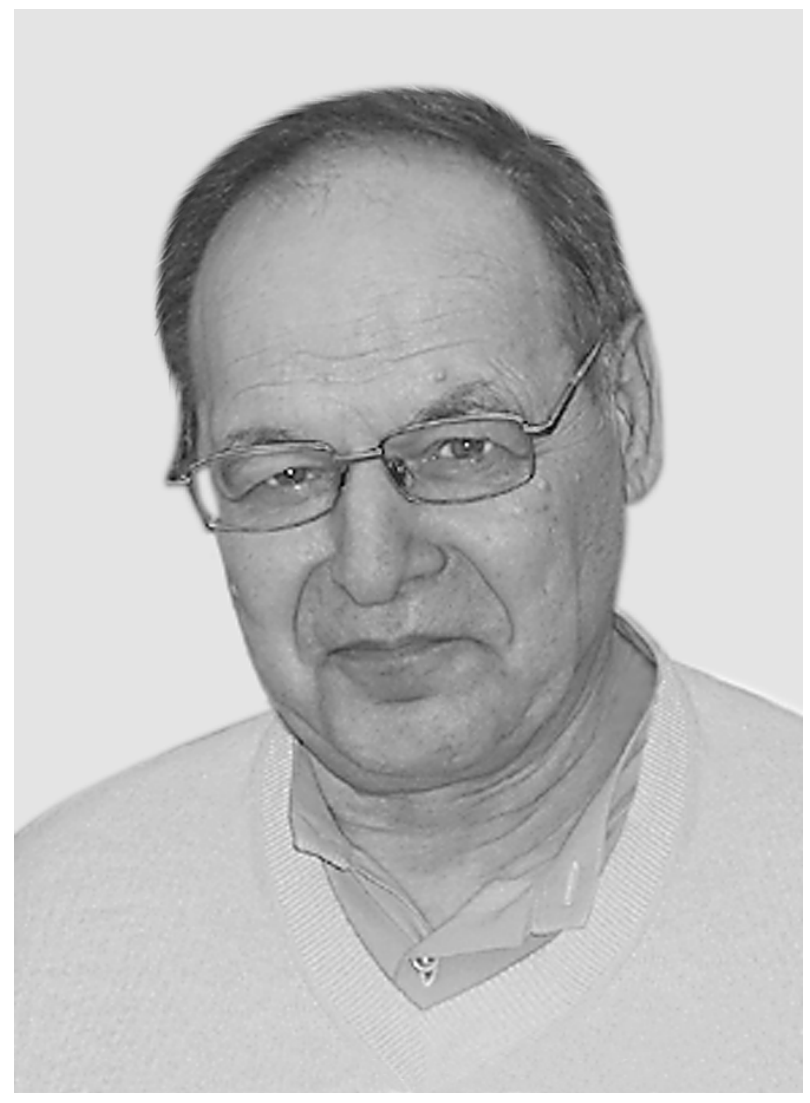

December 26, 2010, marked the 70th birthday of Nikolai Nikolaevich Rosanov, doctor of sciences (Phys.-Math.), professor, deputy editor-in-chief of the journal Optika i spektroskopiya (Optics and Spectroscopy), and a major specialist in the field of laser physics, physical and nonlinear optics, and soliton physics.

Rosanov was born in Leningrad, and his entire life has been tied to this city. Having graduated from high school in 1958, he entered Leningrad State University (today St. Petersburg State University), after graduating from which in 1963, he began work at the Vavilov State Optics Institute, where he traveled the path from engineer to head of the Theory Department. Rosanov's very first works, devoted to Lamb laser theory, demonstrated that a promising scientist had entered laser optics. Subsequent works on optical memory, hysteresis, and nonlinear laser phenomena confirmed this. The results obtained thereof laid the basis for his candidate and doctoral dissertations. After defending the latter, Rosanov concentrated his main interest on such nonlinear phenomena as solitons. In addition, recently, he conducted a cycle of works on relativistic optics. He is the author of more than 350 scientific papers and 12 monographs. His achievements were recognized in 2007 with a D.S. Rozhdestvenskii Award of the Russian Academy of Sciences.

Rosanov's works are widely known both in Russia and abroad. He has been and continues to be invited to read papers at international conferences and foreign universities. He is chairman of the program committee of the international conference Laser Optics.

Along with scientific work, Rosanov carries out a great deal of pedagogical activity; for many years he has been a professor and is now the head of the chair of St. Petersburg State University of Information Technology, Mechanics, and Optics.

The editorial board and staff of the journal and his colleagues congratulate Nikolai Nikolaevich on this jubilee and wish him good health and further success in his scientific and pedagogical activity. 